\title{
The Use of Modern Multimedia Trends for Popularization of Mechatronics by Presenting Its Present and Future Application
}

\author{
Erik Kučera, Oto Haffner, Roman Leskovský, Jakub Matišák and Peter Drahoš \\ Faculty of Electrical Engineering and Information Technology \\ Slovak University of Technology in Bratislava \\ Bratislava, Slovakia \\ Email: erik.kucera@stuba.sk
}

\begin{abstract}
Mechatronics belongs to the modern fields of the science and technology. Modern mechatronics combines mechanics, electronics, automation and informatics. However, young people often understand mechatronics as a combination of mechanics and electronics. This erroneous paradigm brings many problems in education and industry. Actual trend in the industry is Industry 4.0 - also called as fourth industrial revolution. It is a collective name for current automation, exchanging of data and manufacturing technologies. Today's industry (digital factories) is full of information and communication technologies such as Internet of Things, virtual / mixed reality, cloud computing, etc. Unfortunately, only small amount of high school pupils would like to study mechatronics because young generation is influenced by the outdated perception of this field and does not perceive some of its new aspects. They do not see modern technologies in this field. The authors of the paper decided to present mechatronics as a modern branch in an original way - by a fanfilm inspired by Avengers: Infinity War.
\end{abstract}

\section{INTRODUCTION}

I $\mathrm{N}$ THE past, the industry was affected by technological change and innovation. These paradigms are called industrial revolutions. These revolutions were caused by mechanization (1st industrial revolution), use of electrical energy (2nd industrial revolution) and electronics and automation (3rd industrial revolution). All these industrial revolutions did not influence only the production itself, but also the labour market and the educational system as well. As a result of these changes some professions and jobs disappeared. Currently, due to the development of digitalization and robotics, we are facing the next industrial revolution, known as the Industry 4.0. It is expected that some professions will be replaced. The emerging technologies have huge effect on the education of people. Only qualified and highly educated employees will be able to control these technologies. The industry should collaborate with universities. The main vision the following of Industry 4.0 is the emergence of "smart factories", that will be connected to the production facilities Cyber-physical systems called CPS. Using of the Internet of Things, the Internet of Services and the Internet of People will make connection: machine-machine, human-machine or human-human, and at the same time an enormous amount of data will be obtained [1]. For this reason it will be necessary to analyse large data

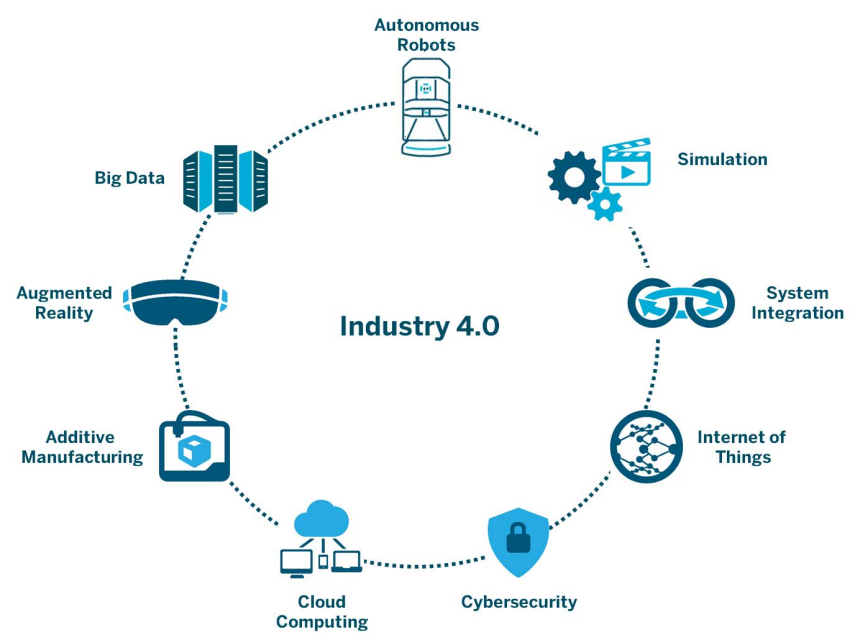

Fig. 1. Modern technologies for Industry 4.0 [4]

(Big Data) to be able to predict possible failures and adapt in real time to the changed conditions [2].

Now, let's analyze the Industry 4.0 impact on mechatronics. This should include the state-of-the-art in research, education and development of control methods, control structures, information a communications technologies. Their applications in different types of industrial processes with the focus on mechatronic systems and the new trends declared in Industry 4.0 should be considered, as well [3].

Mechatronics merges methodology and basic principles of four close scientific disciplines: automation, information and communication technologies (ICT) and mechanics. Thereby it represents an excellent example of a multidisciplinary engineering and points out how an integration of disciplines leads to new degrees of freedom in the corresponding new forms of education [3] [5].

Multidisciplinary education in mechatronics for Industry 4.0 enables an engineer to perform initial design work in mechanical, electrical, automation, control engineering and information technologies and to communicate effectively with 


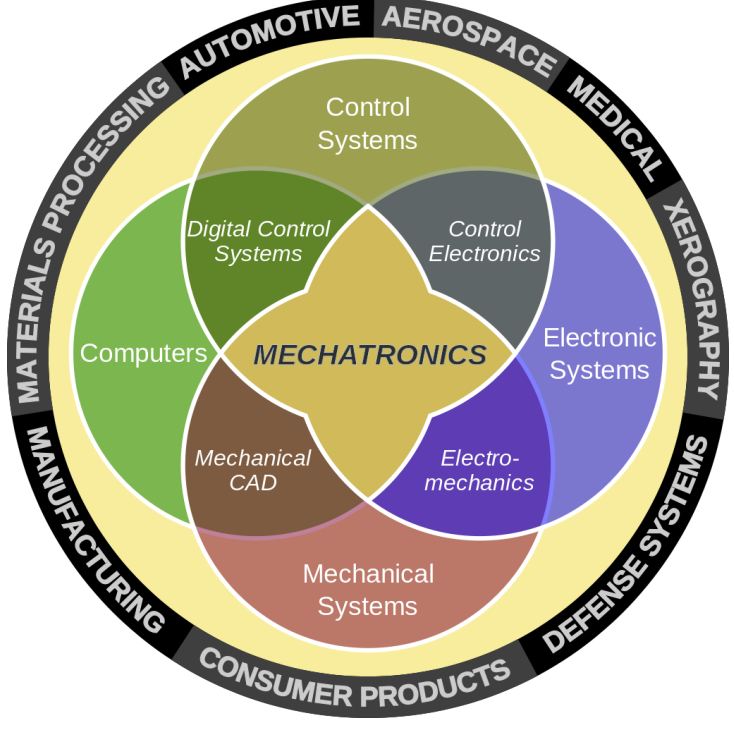

Fig. 2. Mechatronics diagram

specialized design engineers in different disciplines (mechanical, electrical, ICT, power, etc.). Universities need to shape their engineering curricula to better prepare students for professional practice [3].

Nowadays, modern technologies such as cloud, artificial intelligence, Internet of Things, virtual and augmented reality, etc., are used in mechatronics. According to the definition, mechatronics synergistically combines informatics, automation, mechanics, and electronics into a single integrated whole (Fig. 2). To get a mechatronic device, the 4 fields and the individual components of the device have to be effectively interconnected; the binder are smart technologies. Still, smart technologies cannot be considered as a fifth extra field of mechatronics but rather a "soul" of the mechatronic product without which its individual components would not work as a whole.

Unfortunately, only small amount of high school pupils would like to study mechatronics because young generation is influenced by the outdated perception of this field and does not perceive some of its new aspects. They do not see modern or information and communication technologies in this field. As it was stated, this is not true at all. The authors of the paper decided to present mechatronics as a modern branch in an original way.

\section{Popularization of Mechatronics Using Multimedia}

The authors decided to inspire with the very successful promotional videos of the universities that were inspired by the popular film theme (Wolf from VUT - Wolf from Wall Street [6] or Join the FEI STU - Star Wars [7].

Nowadays, modern technologies or multimedia are used in education or popularization of science [8] [9] [10] [11] [12].

During discussions and polls for high school students, it was found that high school students do not know what to imagine under the field of mechatronics. They have often lived with very old understanding of mechatronics as a combination of mechanics and electronics or electrical engineering. This is not mechatronics but electromechanics. It is therefore necessary to draw the young generation's attention to this modern engineering field in a popular way with the expected viral effect. It is more and more challenging to take interest of the young generation (influenced by high-budget production of films and series from Hollywood) in audiovisual work, and especially in education or science and technology. The more emphasis has to be placed on the production quality. Today's young people are used to the high quality video and the aforementioned highbudget production and will not be satisfied with the average audiovisual quality of the final product. Therefore, the use of a well-known theme can support an interest in viewing such a work, which, however, must be processed at an adequate level.

The authors decided to make a fanfilm inspired by Avengers: Infinity War [13]. The aim of the film is to introduce mechatronics to the young generation in an attractive way as a modern 21 st century discipline that combines informatics, automation, mechanics and electronic systems. In the fanfilm, the parallel between the aspects of the universe (= Infinity Stones from Avengers: Infinity War) and the 4 parts of mechatronics (= Mechatronics Stones) are used. The fifth stone is a source of tension and surprise moment.

Many industrial and service equipment as well as consumer products are based on the combination of mechanical and electronic components. However, machines, devices, equipment and products are becoming mechatronic only when they have some degree of "intelligence" as a result of the modern development of electronics, information-communication and control technologies (automation).

As it was stated, to get a mechatronic device, the 4 fields and the individual components of the device have to be effectively interconnected; the binder are smart technologies. So , the fifth stone represents smart technologies.

Our fanfilm was named as Avengers: Five Mechatronics Stones (in Slovak: Avengeri: Pät' kameňov mechatroniky). It has about 10 minutes.

\section{PREPROdUCTION OF FANFILM}

The comparison between the Infinity Stones and the fields of mechatronics area came as a very interesting idea for a promotional video. We had filmed more promotional and education videos at the Institute of Automotive Mechatronics at the Faculty of Electrical Engineering and Information Technology, Slovak University of Technology in Bratislava. But these videos were simpler and shorter. Thus, the story was written, and the screenplay was gradually developed and the filming started. Since the beginning, we have realized that this is our most comprehensive project in the last 10 years.

Restrictions and challenges:

- The use of personnel capital at the Institute - We wanted to make every element of the fanfilm in-house. All participants are from the mentioned Institute or other institutes of our faculty. 


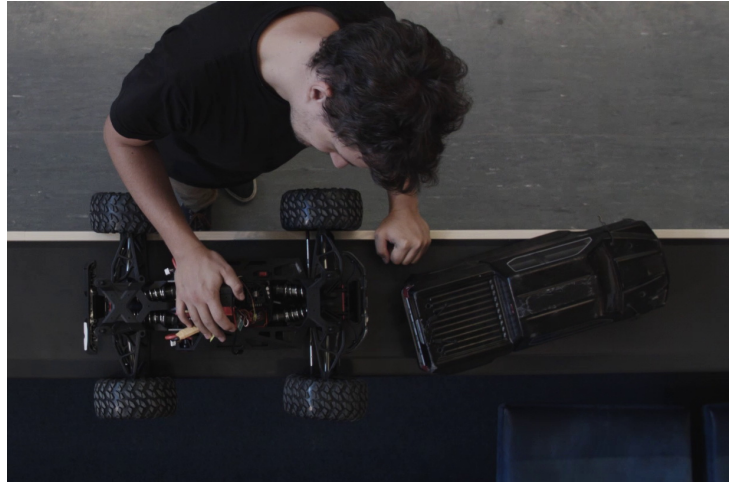

Fig. 3. RC model of car

- Trying to cast girls - It was a huge problem to find willing girl protagonists.

- The use of faculty spaces - They are often not representative and appropriate for popularization and propagation.

- Time restrictions - It was filmed mainly when the semester lessons were not in progress. Even so, it was difficult to match the time schedules of the actors. One of the actors has to be added additionally using chromakeying techniques.

- Won't it be too long? - Should we keep the complete Marvel Cinematic Universe film structure (2 credits + mid-credits scene + after-credits scene)?

- "Zero" budget - The whole project had almost zero budget, colleagues helped us with the passion for work, we used only existing devices, laboratories, video editing software, etc. We only bought a few things inspired by the Marvel Cinematic Universe. Our PhD student is called Erich Stark (resembles Tony Stark in original films), so of course we used this name creatively. Over time, we realized that another of the $\mathrm{PhD}$ students was a bit like Captain America, so we also included this in the video.

We shot the film during seven or eight shooting days. Most of the time it took to prepare a thoughtful screenplay to fit everything together, and especially the very demanding postproduction, as the film contains a large number of special visual effects. Preproduction started practically a few days after the premiere of Avengers: Infinity War. So the whole production lasted about 7-8 months during regular scientific and pedagogical work.

\section{FANFILM ANALYSIS}

The described fanfilm can be seen here (English subtitles can be turned on): https://youtu.be/RtROkZqU6ns or http:// avengers.mechatronika.cool/.

\section{A. Introduction in space}

In the introduction, by microphone voice individual Mechatronics Stones are explained and also what is mechatronics.

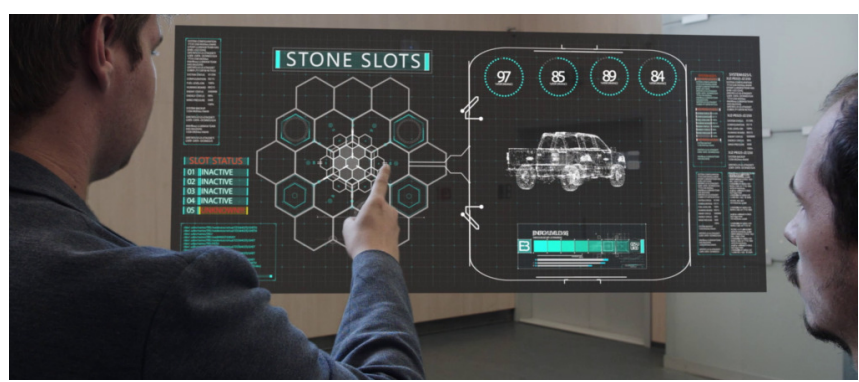

Fig. 4. Slots of Mechatronics Stones

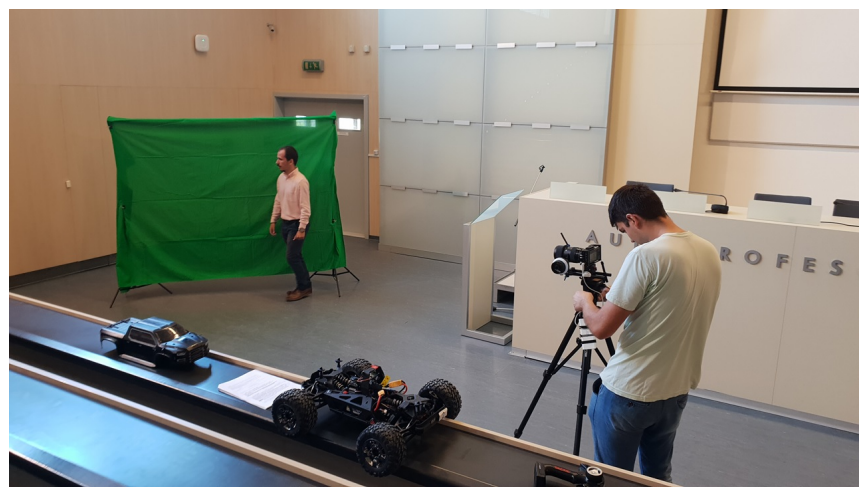

Fig. 5. Chroma-keying

\section{B. Why do we need Mechatronics Stones?}

The main idea of the film is to use stones to make the mechatronic device work. As a device, a mechatronic vehicle model was selected (Fig. 3). Five Mechatronics Stones must be inserted into the virtual slots (Fig. 4). The slots have been filmed using chroma-keying techniques (Fig. 5).

\section{Electronics Stone}

The first stone to be introduced is Electronics Stone (Fig. 7). This section shows the work with electronics (Fig. 6). The result of working with electronics is a programmable LED cube.

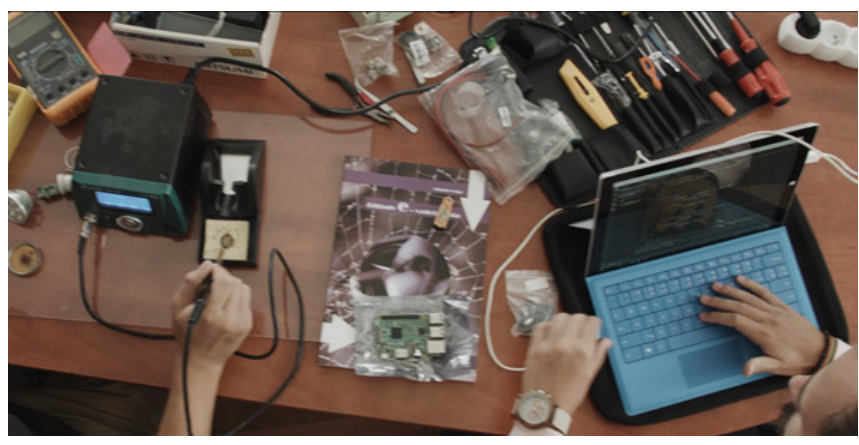

Fig. 6. The work with electronics 


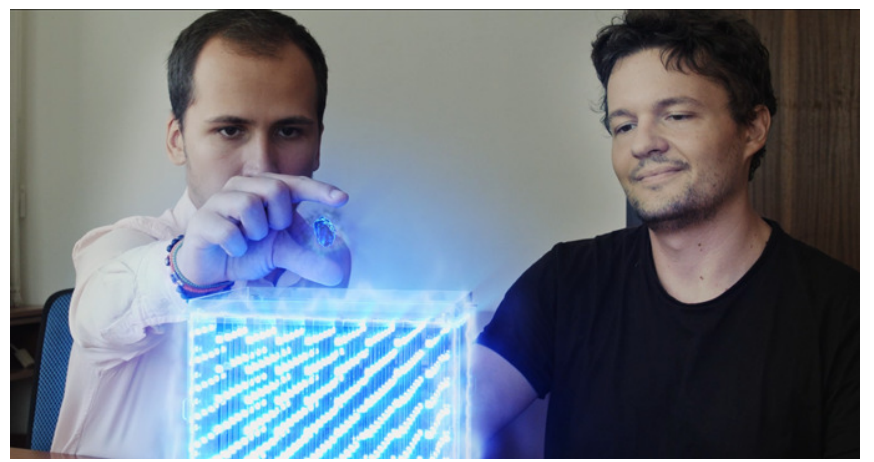

Fig. 7. Electronics Stone

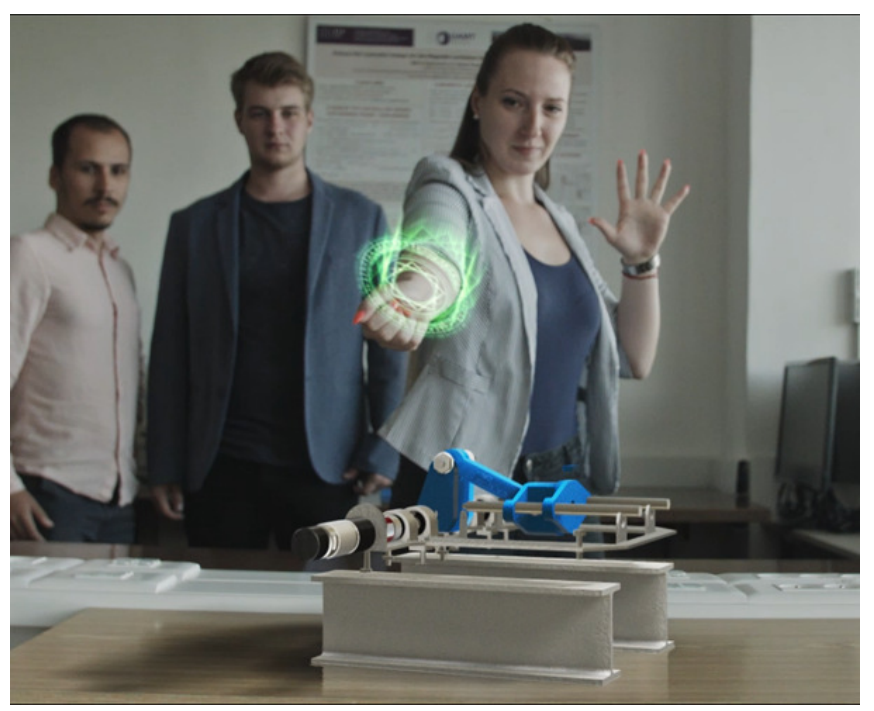

Fig. 8. The use of Mechanics Stone

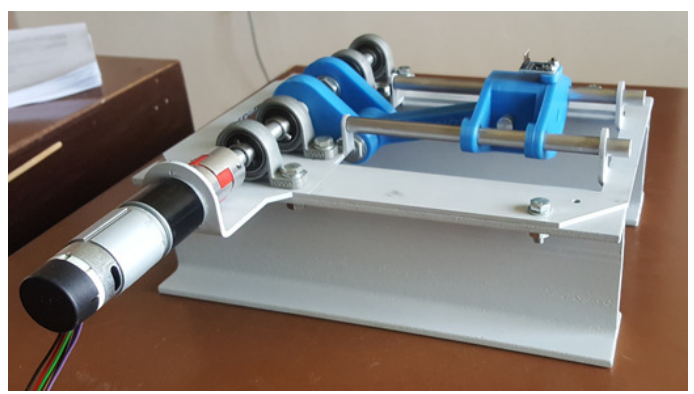

Fig. 9. Real mechanical device

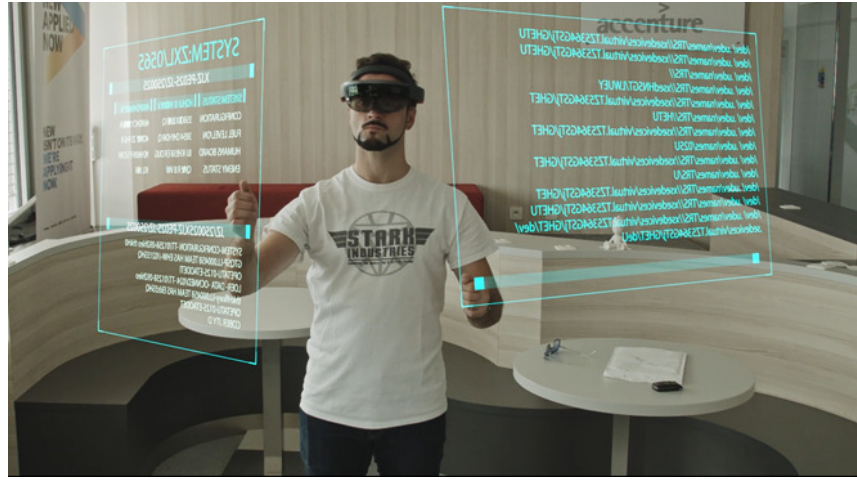

Fig. 10. Microsoft HoloLens and augmented / mixed reality

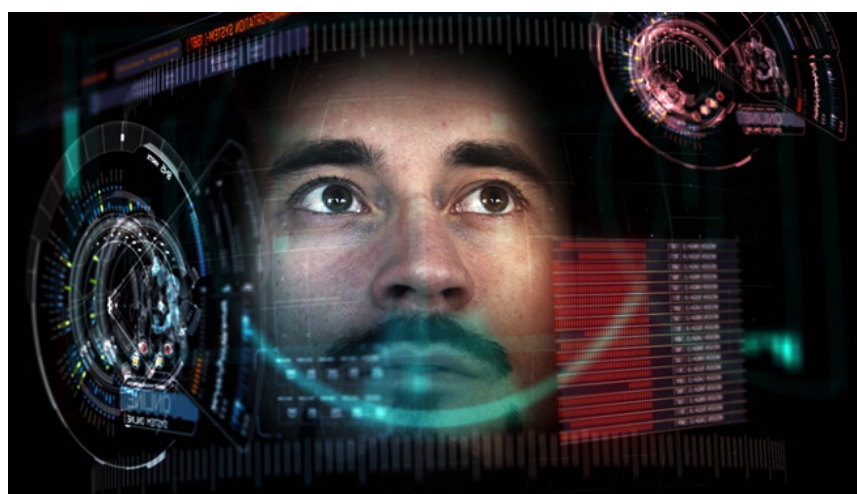

Fig. 11. Iconic shot of Erich Stark inspired by Iron Man

\section{Mechanics Stone}

The second stone is the Mechanics Stone. It is inspired by the Time Stone from original films. Using the Mechanics Stone, a device is constructed (Fig. 8). At our institute, the displayed device is really available (Fig. 9).

\section{E. Informatics Stone}

The third stone is the Informatics Stone. Our PhD student Erich Stark (Fig. 11) - is introduced. Informatics is presented by augmented / mixed reality and by holographic device Microsoft HoloLens (10).

\section{F. Automation Stone}

The last part of mechatronics is automation. Automation is presented by a model of magnetic levitation (Fig. 12). The Automation Stone is hidden in a ball controlled by magnets (Fig. 13).

\section{G. Smart Technologies Stone}

The protagonists found that with four Mechatronics Stones the device did not work (Fig. 14). Smart technologies are needed to link fields of mechatronics. Smart technologies Stone is located in glasses (Fig. 15) of a new hero. Glasses are a symbol of intelligence. The stones are joined and the device works (Fig. 16). 


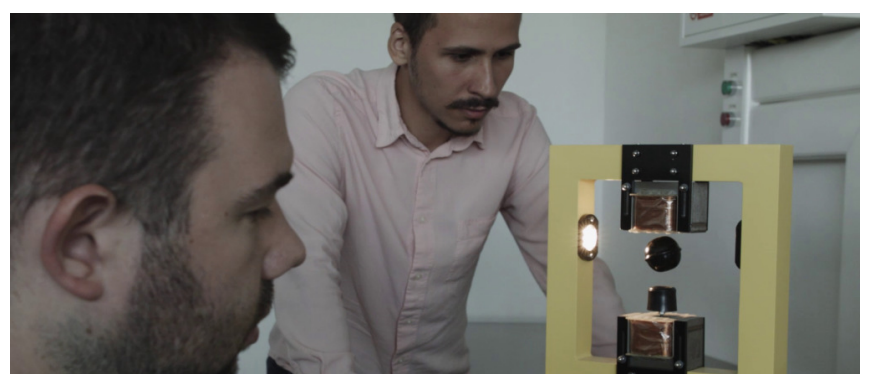

Fig. 12. Magnetic levitation model

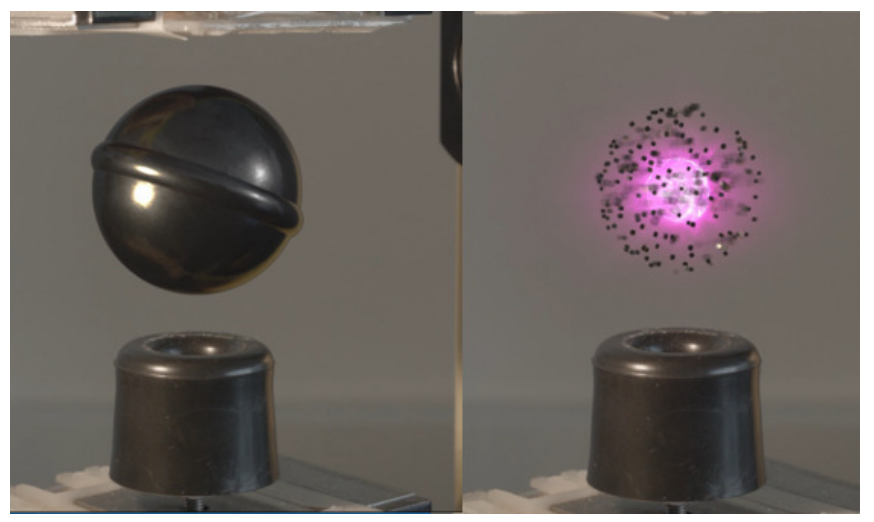

Fig. 13. Automation Stone

\section{H. The end and mid-credits scene}

The new hero turns to be an antagonist. He use the stones and snaps his fingers. Then our protagonists are turned into the dust (Fig. 17).

\section{CRitical Response}

The described fanfilm achieved critical success (Fig. 18). It has about 14,000 views on 14/05/2019 on YouTube. Many Slovak media published articles about fanfilm: Nový Čas (online and print) [14], Refresher [15], Start it up [16], etc. Also, about fanfilm was written abroad [17].

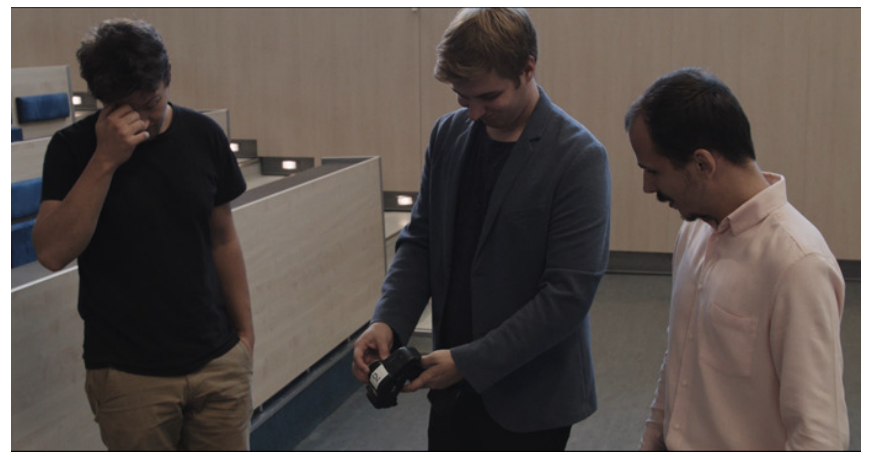

Fig. 14. The device does not work

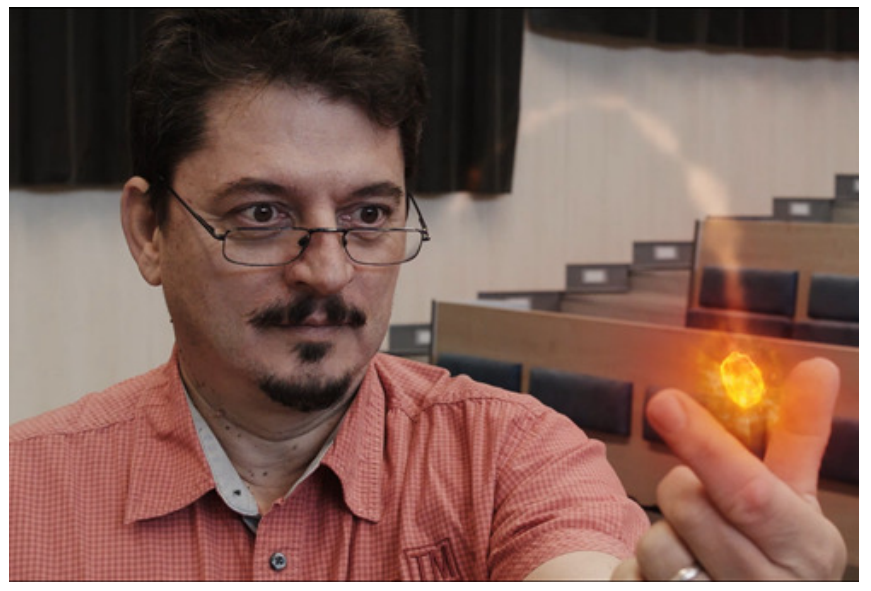

Fig. 15. Smart technologies Stone is located in glasses

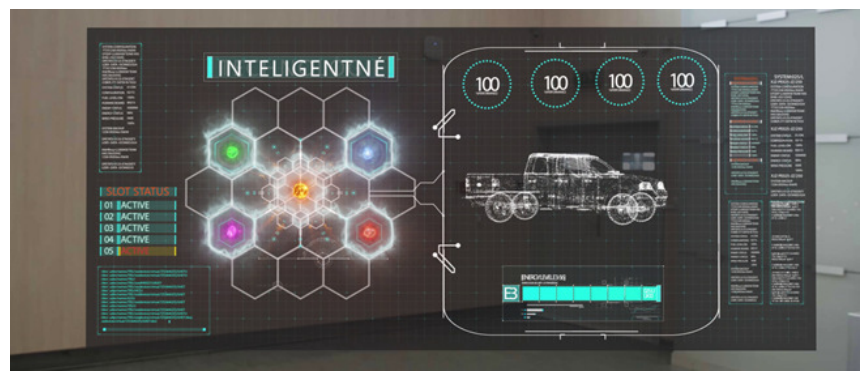

Fig. 16. All Mechatronics Stones

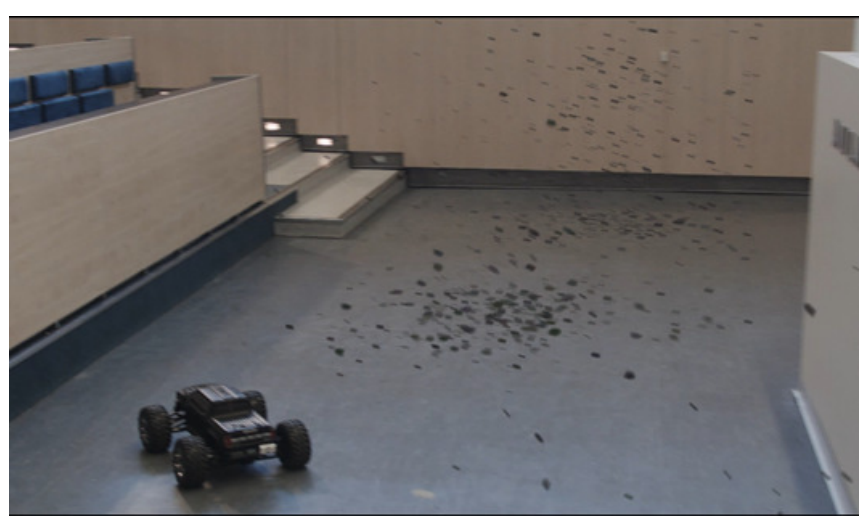

Fig. 17. Mid-credits scene

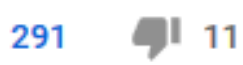

Fig. 18. Likes and dislikes on YouTube (14/05/2019) 


\section{CONCLUSION}

Multidisciplinary education in mechatronics for Industry 4.0 enables an engineer to perform initial design work in mechanical, electrical, automation, control engineering and information technologies and to communicate effectively with specialized design engineers in different disciplines (mechanical, electrical, ICT, power, etc.). Nowadays, modern technologies such as cloud, artificial intelligence, Internet of Things, virtual and augmented reality, etc., are used in mechatronics. Unfortunately, only small amount of high school pupils would like to study mechatronics because young generation is influenced by the outdated perception of this field and does not perceive some of its new aspects. The authors of the paper decided to present mechatronics as a modern branch in an original way - by the fanfilm inspired by Avengers: Infinity War. The described popularization fanfilm achieved critical success and appeared in mass media.

\section{ACKNOWLEDGMENT}

This work has been supported by the Cultural and Educational Grant Agency of the Ministry of Education, Science, Research and Sport of the Slovak Republic, KEGA 030STU4/2017 and KEGA 038STU-4/2018, by the Scientific Grant Agency of the Ministry of Education, Science, Research and Sport of the Slovak Republic under the grant VEGA $1 / 0733 / 16$, and by the Young researchers support program, project No. 1324 - VZRI4 (Virtual and Mixed Reality for Industry 4.0) and project No. 1327 - VTOVI (Virtual Training of Production Operators for Industry 4.0).

\section{REFERENCES}

[1] T. Lojka, P. Satala, J. Mocnej, and I. Zolotová, "Web technologies in industry hmi," 09 2015. doi: 10.1109/INES.2015.7329647 pp. 103-106.

[2] A. Benešová and J. Tupa, "Requirements for education and qualification of people in industry 4.0," Procedia Manufacturing, vol. 11, pp. 2195 - 2202, 2017. doi: https://doi.org/10.1016/j.promfg.2017.07.366 27th International Conference on Flexible Automation and Intelligent Manufacturing, FAIM2017, 27-30 June 2017, Modena, Italy.
[Online]. Available: http://www.sciencedirect.com/science/article/pii/ S2351978917305747

[3] M. Huba and Š.. Kozák, "From e-learning to industry 4.0," in 2016 International Conference on Emerging eLearning Technologies and Applications (ICETA), Nov 2016. doi: 10.1109/ICETA.2016.7802083 pp. 103-108.

[4] T. Melanson. (2018) What industry 4.0 means for manufacturers. [Online]. Available: https://aethon.com/mobile-robots-and-industry4-0/

[5] S. Kozak, E. Ruzicky, J. Stefanovic, and F. Schindler, "Research and education for industry 4.0: Present development," in 2018 Cybernetics \& Informatics (K\&I), Feb 2018, pp. 1-7.

[6] M. Balík and et al. (2014) Wolf of but (in czech). [Online]. Available: https://youtu.be/cCNpNpni6rY

[7] J. Seewald and et al. (2017) Join the fei stu (in slovak). [Online]. Available: https://youtu.be/xrF6L3Uc1Ik

[8] J. Filanova, "Application of didactic principles in the use of videoconferencing in e-learning (in slovak)," in Innovation process in e-learning. EKONOM, March 2013. ISBN 978-80-225-3610-3 pp. 1-7.

[9] K. Zhang, J. Suo, J. Chen, X. Liu, and L. Gao, "Design and implementation of fire safety education system on campus based on virtual reality technology," in 2017 Federated Conference on Computer Science and Information Systems (FedCSIS). IEEE, 2017. doi: 10.15439/2017F376

[10] J. Majernik, M. Madar, and J. Mojzisova, "Integration of virtual patients in education of veterinary medicine," in 2017 Federated Conference on Computer Science and Information Systems (FedCSIS). IEEE, 2017. doi: $10.15439 / 2017 \mathrm{~F} 134$

[11] K. Szklanny, Ł. Homoncik, M. Wichrowski, and A. Wieczorkowska, "Creating an interactive and storytelling educational physics app for mobile devices," in 2017 Federated Conference on Computer Science and Information Systems (FedCSIS), Sep. 2017. doi: 10.15439/2017F95 pp. 1269-1273.

[12] R. R. Gajewski, "Pitfalls of e-education: From multimedia to digital dementia?" in 2016 Federated Conference on Computer Science and Information Systems (FedCSIS), Sep. 2016, pp. 913-920.

[13] Marvel. (2018) Avengers: Infinity war. [Online]. Available: https: //www.marvel.com/movies/avengers-infinity-war

[14] A Galajdová (2019) Stu students want to convince that their field is not as boring as many think: You will see the video, you will be amazed! (in slovak). [Online]. Available: https://www.cas.sk/clanok/ 811257/studenti-z-stu-chcu-presvedcit

[15] J. Paulík. (2019) Slovak students shooted a film inspired by the avengers (in slovak). [Online]. Available: https://filmkult.refresher.sk/ 13207-Slovenski-vysokoskolaci-natocili-film-inspirovany-Avengers

[16] V. Andorová. (2019) Slovak students shooted a short film inspired by the avengers for almost zero costs (in slovak). [Online]. Available: https://bit.ly/2vZ48qm

[17] D. Hanuš. (2019) Avengers: Five mechatronics stones or marvel's competition in bratislava (in czech). [Online]. Available: https: //bit.ly/30gx37f 